RESEARCH REPORT

\title{
Social class inequalities in perinatal outcomes: Scotland 1980-2000
}

\section{Fairley, A H Leyland}

J Epidemiol Community Health 2006;60:31-36. doi: 10.1136/jech.2005.038380

See end of article for authors' affiliations

\section{Correspondence to:}

Lesley Fairley, MRC Social and Public Health Sciences Unit, University of

Glasgow, 4 Lilybank

Gardens, Glasgow G12

8RZ, UK; L.Fairley@msoc.

mrc.ac.uk

Accepted for publication 16 September 2005

\begin{abstract}
Objective: To examine social class inequalities in adverse perinatal events in Scotland between 1980 and 2000 and how these were influenced by other maternal risk factors.

Design: Population based study using routine maternity discharge data.

Setting: Scotland.

Participants: All women who gave birth to a live singleton baby in Scottish hospitals between 1980 and 2000 ( $n=1282$ 172).

Main outcome measures: Low birth weight (LBW), preterm birth, and small for gestational age (SGA).

Results: The distribution of social class changed over time, with the proportion of mothers with undetermined social class increasing from $3.9 \%$ in $1980-84$ to $14.8 \%$ in $1995-2000$. The relative index of inequality (RII) decreased during the 1980s for all outcomes. The RII then increased between the early and late 1990s (LBW from $2.09(95 \% \mathrm{Cl} 1.97,2.22)$ to $2.43(2.29,2.58)$, preterm from $1.52(1.44,1.61)$ to $1.75(1.65,1.86)$, and SGA from $2.28(2.14,2.42)$ to $2.49(2.34,2.66)$ respectively). Inequalities were greatest in married mothers, mothers aged over 35 , mothers taller than $164 \mathrm{~cm}$, and mothers with a parity of one or more. Inequalities were also greater by the end of the 1990s than at the start of the 1980s for women of parity one or more and for mothers who were not married.

Conclusion: Despite decreasing during the 1980s, inequalities in adverse perinatal outcomes increased during the 1990s in all strata defined by maternal characteristics.
\end{abstract}

L ow birth weight (LBW), preterm birth, and small for gestational age (SGA) are used as indicators to monitor -adverse perinatal outcomes. Birth weight and gestational age are the main determinants for neonatal and infant death. ${ }^{12}$ Growth in utero is associated with health in later life; poor fetal growth is associated with an increased risk of adult diseases such as hypertension, diabetes, and coronary heart disease. ${ }^{3}$

Parental occupational social class is associated with adverse perinatal outcomes. ${ }^{4}$ Rates of LBW, preterm, and SGA births are higher among the manual social classes than the non-manual. Social class is also related to other maternal factors. Maternal age, marital status, height, and parity are all associated with social class. ${ }^{5-10}$ Mothers from lower social classes are more likely to be young, single, shorter, and of high parity. However, these distributions have changed over the past 20 years. ${ }^{11}$ There has been an increase in the proportion of older mothers, single mothers, taller mothers, and mothers with undetermined social class (this group includes people with inadequate job description, never worked, housewives, and students). The interactions between social class and other maternal factors and the changing distributions create problems for assessing social inequalities.

Recent trends in England and Wales have shown that inequalities in LBW did not decrease throughout the 1990s. ${ }^{12}$ In Finland, however, social inequalities in adverse perinatal events diminished. ${ }^{9}$ We previously found that in Scotland between 1980 and 2000 inequalities in LBW had a quadratic relation over time, with inequalities across social classes actually increasing during the 1990s. ${ }^{11}$ In this paper we investigate the relations between social class and the other maternal risk factors over time to see if we can identify in which groups of women inequalities in LBW were greatest, and which groups have contributed to the increase in inequality in LBW seen in 1990s. In addition to LBW we also consider preterm births and SGA as outcomes to describe trends in perinatal health in Scotland.

\section{METHODS \\ Data}

We used data from 1282172 live singleton births-all such hospital births in Scotland between 1980 and 2000-linked to the registrar general's birth registrations to obtain the occupational social class of the father (or the mother if the father's occupation was not recorded). The outcomes considered were: LBW $(<2500 \mathrm{~g})$, preterm births ( $<37$ weeks' gestation), and SGA defined as those babies falling on or below the 5 th centile of the appropriate sex and gestation specific distribution of the study population. Gestational age at birth was defined as the number of completed weeks of gestation based on the estimated delivery date in the clinical record. Year of birth was split into four time periods of five years.

Occupational social class was coded according to the registrar general's classification into one of seven groups; professional (I), managerial/technical (II), skilled nonmanual (IIINM), skilled manual (IIIM), semi-skilled (IV), unskilled (V), and undetermined. The undetermined group have consistently poorer outcomes than the other social classes. ${ }^{11}$

Maternal factors studied were maternal age $(<20,20-34$, and 35+), marital status (married (including cohabiting), single and other (including divorced, separated, widowed, and not known)), maternal height $(<155 \mathrm{~cm}, 155-163 \mathrm{~cm}$, and $\geqslant 164 \mathrm{~cm})$, and parity $(0,1-2$, and $3+)$.

Birth weight was missing on 1016 records and there were 108 records with birth weight less than 500 g; these subjects were excluded from analysis. Gestational age was missing on

Abbreviations: LBW, low birth weight; SGA, small for gestational age; RII, relative index of inequality 
Table 1 Distribution of parental social class of live singleton births, Scotland 1980-2000

\begin{tabular}{|c|c|c|c|c|c|c|c|c|}
\hline \multirow[b]{3}{*}{ Social class } & \multirow{2}{*}{\multicolumn{2}{|c|}{$\frac{1980-84}{N=304627}$}} & \multirow{2}{*}{\multicolumn{2}{|c|}{$\begin{array}{l}1985-1989 \\
N=289479\end{array}$}} & \multirow{2}{*}{\multicolumn{2}{|c|}{$\begin{array}{l}1990-1994 \\
N=283032\end{array}$}} & \multirow{2}{*}{\multicolumn{2}{|c|}{$\begin{array}{l}1995-2000 \\
N=281001\end{array}$}} \\
\hline & & & & & & & & \\
\hline & $n$ & $\%$ & $n$ & $\%$ & $\mathbf{n}$ & $\%$ & $\mathbf{n}$ & $\%$ \\
\hline 1 & 21451 & 7.0 & 20188 & 7.0 & 18880 & 6.7 & 19375 & 6.9 \\
\hline II & 50787 & 16.7 & 49075 & 17.0 & 53620 & 18.9 & 60073 & 21.4 \\
\hline IIInm & 39219 & 12.9 & 44408 & 15.3 & 38129 & 13.5 & 42689 & 15.2 \\
\hline IIIm & 103893 & 34.1 & 85000 & 29.4 & 65853 & 23.3 & 59702 & 21.3 \\
\hline IV & 48551 & 15.9 & 52703 & 18.2 & 52075 & 18.4 & 42804 & 15.2 \\
\hline V & 28846 & 9.5 & 20431 & 7.1 & 24673 & 8.7 & 14763 & 5.3 \\
\hline Undetermined & 11880 & 3.9 & 17674 & 6.1 & 29802 & 10.5 & 41595 & 14.8 \\
\hline
\end{tabular}

5322 records and 501 had gestation less than 24 weeks and were also excluded. The SGA indicator could not be assigned to 25 infants because of missing information on their sex. Maternal age was missing on 25 records and parity on 10 records. Maternal height was missing on 117046 (9.1\%) records; a high proportion (46 604, 40\%) of these missing values occurred between 1995 and 2000. In total 1158139 (90.3\%) births had complete data and were used in the analysis.

\section{Statistical methods}

The relation between social class and each outcome was estimated using logistic regression. Social class I was the reference category.

To compare the changes in social class inequalities in perinatal outcomes over time the relative index of inequality (RII) was used..$^{13-15}$ This takes into account the fact that the proportion of the population in each social class at each time point differs. Social class was defined hierarchically (I, II, IIINM, IIIM, IV, V, and undetermined) and each group was assigned a value between 0 and 1 depending on the proportion of the population with higher socioeconomic position than the midpoint of each group within the hierarchy. Socioeconomic position was then related to the outcomes through logistic regression. The resulting odds ratio compares the bottom of the social hierarchy with the top; the larger the RII the larger the inequality. The RII was calculated for each time period. Separate models including the interaction between each of the maternal risk factors and the RII were fitted for each time period. The significance of the interaction term was assessed by a Wald test.

\section{RESULTS}

The social class distribution changed dramatically. The proportion of mothers in social class II, IIINM, and with undetermined social class increased from $16.7 \%$ to $21.4 \%$, from $12.9 \%$ to $15.2 \%$, and from $3.9 \%$ to $14.8 \%$ respectively (table 1). Mean maternal age increased by two years from 26 years in the early 1980s to 28 years in the late 1990s (table 2). Mean maternal height also increased over time from $160 \mathrm{~cm}$ to $163 \mathrm{~cm}$. The proportion of single mothers increased from $8.6 \%$ to $26.3 \%$.

Table 2 Maternal characteristics of live singleton births by social class and time, Scotland 1980-2000

\begin{tabular}{|c|c|c|c|c|c|c|c|c|c|}
\hline \multirow[b]{2}{*}{ Maternal age } & \multirow{2}{*}{$\begin{array}{l}\text { Social class } \\
\text { I }\end{array}$} & \multicolumn{2}{|c|}{$1980-1984$} & \multicolumn{2}{|c|}{ 1985-1989 } & \multicolumn{2}{|c|}{ 1990-1994 } & \multicolumn{2}{|c|}{ 1995-2000 } \\
\hline & & 28.6 & 4.5 & 29.2 & 4.6 & 30.6 & 4.1 & 31.6 & 4.1 \\
\hline \multirow[t]{7}{*}{ Mean and SD, years } & $\|$ & 28.2 & 4.6 & 28.7 & 4.6 & 29.4 & 4.6 & 30.5 & 4.7 \\
\hline & IIInm & 25.2 & 5.0 & 25.7 & 5.0 & 26.3 & 5.2 & 27.2 & 5.6 \\
\hline & $\mathrm{Illm}$ & 25.7 & 4.8 & 26.4 & 4.7 & 27.3 & 4.8 & 28.6 & 4.9 \\
\hline & IV & 24.9 & 5.0 & 25.0 & 4.9 & 26.4 & 4.9 & 27.2 & 5.4 \\
\hline & V & 24.2 & 4.9 & 24.6 & 4.7 & 26.1 & 4.8 & 27.6 & 5.1 \\
\hline & Undetermined & 22.5 & 5.8 & 21.9 & 5.2 & 23.8 & 5.5 & 24.4 & 6.1 \\
\hline & Total & 25.9 & 5.1 & 26.2 & 5.1 & 27.1 & 5.2 & 28.1 & 5.6 \\
\hline Maternal height & 1 & 162.2 & 6.2 & 162.6 & 6.2 & 163.4 & 6.3 & 164.0 & 6.3 \\
\hline \multirow[t]{7}{*}{ Mean and SD, $\mathrm{cm}$} & $\|$ & 161.5 & 6.2 & 162.0 & 6.2 & 162.7 & 6.3 & 163.4 & 6.4 \\
\hline & IIInm & 160.5 & 6.3 & 161.3 & 6.3 & 161.9 & 6.4 & 162.8 & 6.5 \\
\hline & $\mathrm{Illm}$ & 159.9 & 6.2 & 160.7 & 6.2 & 161.7 & 6.3 & 162.4 & 6.4 \\
\hline & IV & 159.7 & 6.2 & 160.4 & 6.3 & 161.4 & 6.4 & 162.2 & 6.5 \\
\hline & V & 159.0 & 6.2 & 159.8 & 6.3 & 161.2 & 6.5 & 162.1 & 6.6 \\
\hline & Undetermined & 159.3 & 6.2 & 159.8 & 6.2 & 161.0 & 6.5 & 161.9 & 6.5 \\
\hline & Total & 160.3 & 6.3 & 161.0 & 6.3 & 161.8 & 6.4 & 162.7 & 6.5 \\
\hline \multirow[t]{8}{*}{ Single mothers, \% } & 1 & 2.9 & & 3.4 & & 1.7 & & 4.0 & \\
\hline & $\|$ & 3.2 & & 5.9 & & 9.2 & & 13.4 & \\
\hline & IIInm & 14.5 & & 24.8 & & 31.4 & & 38.1 & \\
\hline & $\mathrm{IIIm}$ & 2.8 & & 5.7 & & 12.6 & & 13.1 & \\
\hline & IV & 16.6 & & 24.4 & & 22.4 & & 31.3 & \\
\hline & V & 7.4 & & 8.1 & & 20.6 & & 20.5 & \\
\hline & Undetermined & 43.5 & & 63.8 & & 60.4 & & 59.3 & \\
\hline & Total & 8.6 & & 15.6 & & 21.3 & & 26.3 & \\
\hline \multirow{8}{*}{ Parity $3+, \%$} & 1 & 4.9 & & 5.2 & & 4.9 & & 4.9 & \\
\hline & \| & 6.4 & & 6.2 & & 5.2 & & 4.8 & \\
\hline & IIInm & 5.6 & & 4.7 & & 5.0 & & 4.2 & \\
\hline & $\mathrm{IIm}$ & 7.2 & & 7.0 & & 6.0 & & 6.5 & \\
\hline & IV & 7.7 & & 7.7 & & 6.8 & & 6.8 & \\
\hline & V & 10.3 & & 11.7 & & 9.1 & & 10.7 & \\
\hline & Undetermined & 8.1 & & 7.8 & & 8.7 & & 10.1 & \\
\hline & Total & 7.1 & & 6.9 & & 6.3 & & 6.5 & \\
\hline
\end{tabular}




\begin{tabular}{|c|c|c|c|c|c|c|c|c|c|c|c|c|c|}
\hline \multirow[b]{2}{*}{ Social class } & \multicolumn{3}{|c|}{$1980-1984$} & \multicolumn{3}{|c|}{ 1985-1989 } & \multicolumn{3}{|c|}{ 1990-1994 } & \multicolumn{3}{|c|}{$1995-2000$} & \\
\hline & $\%$ & OR & $95 \% \mathrm{Cl}$ & $\%$ & OR & $95 \% \mathrm{Cl}$ & $\%$ & OR & $95 \% \mathrm{Cl}$ & $\%$ & OR & $95 \% \mathrm{Cl}$ & \\
\hline 1 & 3.2 & 1 & & 3.3 & 1 & & 3.0 & 1 & & 2.9 & 1 & & \\
\hline ॥ & 3.9 & 1.21 & $(1.11,1.32)$ & 3.9 & 1.19 & $(1.09,1.30)$ & 3.9 & 1.31 & $(1.19,1.43)$ & 3.8 & 1.34 & $(1.22,1.47)$ & \\
\hline Illnm & 5.3 & 1.67 & $(1.53,1.82)$ & 5.16 & 1.56 & $(1.43,1.70)$ & 5.2 & 1.76 & $(1.60,1.93)$ & 5.2 & 1.84 & $(1.67,2.02)$ & \\
\hline $\mathrm{Illm}$ & 5.4 & 1.68 & $(1.55,1.83)$ & 5.2 & 1.60 & $(1.47,1.74)$ & 5.1 & 1.71 & $(1.56,1.87)$ & 5.1 & 1.81 & $(1.65,1.99)$ & \\
\hline IV & 6.3 & 2.01 & $(1.85,2.19)$ & 6.3 & 1.96 & $(1.80,2.13)$ & 5.8 & 1.97 & $(1.80,2.16)$ & 6.1 & 2.17 & $(1.98,2.39)$ & \\
\hline $\mathrm{V}$ & 6.9 & 2.19 & $(2.01,2.40$ & 6.4 & 2.00 & $(1.82,2.20)$ & 6.2 & 2.11 & $(1.92,2.33)$ & 5.8 & 2.07 & $(1.86,2.31)$ & \\
\hline Undetermined & 14.9 & 5.24 & $(4.78,5.73)$ & 7.8 & 2.48 & $(2.26,2.73)$ & 7.0 & 2.42 & $(2.20,2.66)$ & 7.4 & 2.70 & $(2.47,2.96)$ & \\
\hline Total & 5.6 & & & 5.3 & & & 5.2 & & & 5.2 & & & \\
\hline RII & & & & $p^{*}$ & & & $\mathrm{p}^{*}$ & & & $\mathrm{p}^{*}$ & & & $p^{*}$ \\
\hline Overall & & 2.89 & $(2.73,3.05)$ & & 2.16 & $(2.04,2.29)$ & & 2.09 & $(1.97,2.22)$ & & 2.43 & $(2.29,2.58)$ & \\
\hline Marital status & & & & $<0.001$ & & & $<0.001$ & & & $<0.001$ & & & 0.01 \\
\hline Married & & 2.86 & $(2.68,3.05)$ & & 2.05 & $(1.90,2.20)$ & & 1.96 & $(1.81,2.12)$ & & 2.07 & $(1.89,2.27)$ & \\
\hline Single & & 1.67 & $(1.44,1.95)$ & & 1.43 & $(1.26,1.62)$ & & 1.34 & $(1.20,1.51)$ & & 1.72 & $(1.54,1.91)$ & \\
\hline Other & & 1.59 & $(1.26,2.02)$ & & 1.29 & $(1.06,1.58)$ & & 1.42 & $(1.18,1.70)$ & & 2.18 & $(1.89,2.52)$ & \\
\hline Maternal age & & & & $<0.001$ & & & $<0.001$ & & & $<0.001$ & & & $<0.001$ \\
\hline$<20$ & & 1.56 & $(1.33,1.83)$ & & 1.35 & $(1.14,1.60)$ & & 1.07 & $(0.88,1.30)$ & & 1.25 & $(1.01,1.55)$ & \\
\hline $20-34$ & & 2.88 & $(2.70,3.07)$ & & 2.10 & $(1.96,2.24)$ & & 2.10 & $(1.97,2.25)$ & & 2.31 & $(2.16,2.48)$ & \\
\hline$\geqslant 35$ & & 4.51 & $(3.66,5.56)$ & & 3.26 & $(2.65,4.01)$ & & 2.81 & $(2.33,3.38)$ & & 3.78 & $(3.22,4.43)$ & \\
\hline Maternal height & & & & 0.013 & & & 0.12 & & & 0.58 & & & $<0.001$ \\
\hline$<155 \mathrm{~cm}$ & & 2.19 & $(1.96,2.44)$ & & 1.80 & $(1.60,2.03)$ & & 1.77 & $(1.55,2.02)$ & & 1.89 & $(1.64,2.18)$ & \\
\hline $155 \mathrm{~cm}-164 \mathrm{~cm}$ & & 2.59 & $(2.40,2.80)$ & & 1.84 & $(1.70,1.99)$ & & 1.87 & $(1.72,2.03)$ & & 2.16 & $(1.99,2.35)$ & \\
\hline$>164 \mathrm{~cm}$ & & 2.91 & $(2.56,3.31)$ & & 2.16 & $(1.91,2.45)$ & & 2.03 & $(1.81,2.27)$ & & 2.50 & $(2.25,2.78)$ & \\
\hline Parity & & & & $<0.001$ & & & $<0.001$ & & & $<0.001$ & & & $<0.001$ \\
\hline 0 & & 2.17 & $(2.01,2.35)$ & & 1.57 & $(1.45,1.70)$ & & 1.54 & $(1.42,1.67)$ & & 1.64 & $(1.51,1.78)$ & \\
\hline $1-2$ & & 2.81 & $(2.57,3.07)$ & & 2.28 & $(2.07,2.50)$ & & 2.31 & $(2.10,2.54)$ & & 2.92 & $(2.66,3.21)$ & \\
\hline $3+$ & & 3.08 & $(2.51,3.77)$ & & 2.11 & $(1.71,2.60)$ & & 2.39 & $(1.91,2.98)$ & & 3.08 & $(2.48,3.83)$ & \\
\hline
\end{tabular}

Mothers in social class I were on average four years older than mothers in social class $\mathrm{V}$, and seven years older than mothers with undetermined social class (table 2). Mothers from higher social classes were on average taller than mothers from lower social classes. The proportion of single mothers was greatest in the undetermined social class and also higher in social classes IIINM and IV. Social class V had the highest proportion of mothers with parity of three or more. These patterns were seen across all time periods.

The proportion of LBW and SGA infants decreased over time, from $5.6 \%$ to $5.2 \%$ and from $6.0 \%$ to $4.3 \%$ respectively, while there was a slight increase in the proportion of preterm births from $5.2 \%$ to $5.4 \%$ (tables 3 to 5 ). The time trends varied by social class. For all outcomes the largest decrease was seen in the undetermined social class. The proportion of LBW births in this group fell from $14.9 \%$ to $7.4 \%$, the proportion of preterm births fell from $14.4 \%$ to $6.9 \%$, and the proportion of SGA births fell from $10.4 \%$ to $5.9 \%$.

In each time period there was a significant association between social class and each outcome, with the odds increasing as social class decreased. The odds were consistently highest in the undetermined social class; relative to social class I the odds of adverse perinatal outcomes among children with undetermined parental social class decreased between the early and late 1980s and then increased again between the early and late 1990s (tables 3 to 5 ).

The RII decreased then increased again over time for each outcome. Inequalities between 1995 and 2000 were significantly lower than between 1980 and 1984 for LBW and preterm births; however, they were greater than between 1990 and 1994. For SGA there was no significant difference in the RII between the early 1980s and late 1990s, but again there was an increase in the inequality between the early and late 1990s. The same quadratic pattern in the RII was seen across all levels of the maternal risk factors, with inequalities increasing between the early and late 1990s (tables 3 to 5).

Tables 3 to 5 show the RII for each outcome by each maternal factor. Inequalities tended to be greater in married mothers. For all marital status groups the RII for SGA was greater between 1995 and 2000 than it was between 1980 and 1984. The RII increased as maternal age increased. In 19901994 social inequalities among teenage mothers were not significant for any of the outcomes, but by 1995-2000 were significant for LBW and preterm births. Inequalities in SGA were greater in the late 1990s than the early 1980s for mothers aged over 35. Inequalities increased with maternal height and for mothers with height greater than $155 \mathrm{~cm}$ inequalities in SGA births were greater between 1995 and 2000 than between 1980 and 1984. Inequalities were lowest in mothers with a parity of 0 and about equal for mothers of parity 1-2 or 3+. Inequalities increased between the early and late 1990s for women of all parities, although the increase was less pronounced among primiparous women. Only among primiparous women were social class inequalities consistently lower by the end of the 1990s than at the beginning of the 1980s.

\section{DISCUSSION}

Inequalities in adverse perinatal outcomes existed and were of a similar magnitude in the late 1990s as in the early 1980s, although they decreased in between. The extent of inequality varied by maternal characteristics. Married mothers, mothers aged 35 and over, taller mothers, and mothers with higher parity experienced the greatest inequalities. However, the increase in inequalities seen during the 1990s was most pronounced among the single and other marital status groups, mothers aged 35 and over, mothers of height $155 \mathrm{~cm}$ and over, and mothers with parity 1 or more.

Birth weight and gestational age are collected routinely on maternity discharge forms and the three adverse perinatal outcomes studied here define groups within the population for which preventative interventions may be possible. Low birth weight and preterm delivery are highly correlated, while SGA is a composite measure of birth weight and gestational age. The same patterns and trends were seen for all of the outcomes, in particular the increasing inequalities during the 1990s. 
Table 4 Preterm birth prevalence, odds ratios $(95 \% \mathrm{Cl})$ by social class, and Rll by maternal factors and time, Scotland 19802000

\begin{tabular}{|c|c|c|c|c|c|c|c|c|c|c|c|c|c|}
\hline \multirow[b]{2}{*}{ Social class } & \multicolumn{3}{|c|}{ 1980-1984 } & \multicolumn{3}{|c|}{ 1985-1989 } & \multicolumn{3}{|c|}{ 1990-1994 } & \multicolumn{3}{|c|}{ 1995-2000 } & \\
\hline & $\%$ & OR & $95 \% \mathrm{Cl}$ & $\%$ & OR & $95 \% \mathrm{Cl}$ & $\%$ & OR & $95 \% \mathrm{Cl}$ & $\%$ & OR & $95 \% \mathrm{Cl}$ & \\
\hline 1 & 3.4 & 1 & & 3.9 & 1 & & 3.9 & 1 & & 3.7 & 1 & 1 & \\
\hline ॥ & 4.0 & 1.20 & $(1.10,1.31)$ & 4.2 & 1.09 & $(1.00,1.19)$ & 4.4 & 1.12 & $(1.03,1.21)$ & 4.5 & 1.21 & $(1.11,1.32)$ & \\
\hline IIInm & 4.9 & 1.48 & $(1.36,1.61)$ & 5.1 & 1.34 & $(1.23,1.46)$ & 5.4 & 1.40 & $(1.29,1.53)$ & 5.4 & 1.47 & $(1.35,1.60)$ & \\
\hline $\mathrm{IIIm}$ & 4.8 & 1.42 & $(1.31,1.54)$ & 5.0 & 1.30 & $(1.20,1.41)$ & 5.1 & 1.32 & $(1.22,1.44)$ & 5.4 & 1.46 & $(1.34,1.58)$ & \\
\hline IV & 5.7 & 1.71 & $(1.57,1.85)$ & 5.5 & 1.45 & $(1.33,1.57)$ & 5.4 & 1.40 & $(1.29,1.52)$ & 5.9 & 1.60 & $(1.47,1.74)$ & \\
\hline$\vee$ & 5.8 & 1.75 & $(1.60,1.91)$ & 5.5 & 1.45 & $(1.32,1.59)$ & 5.5 & 1.43 & $(1.30,1.56)$ & 5.7 & 1.56 & $(1.41,1.73)$ & \\
\hline Undetermined & 14.4 & 4.78 & $(4.37,5.23)$ & 7.1 & 1.91 & $(1.74,2.09)$ & 6.5 & 1.70 & $(1.56,1.85)$ & 6.9 & 1.90 & $(1.75,2.07)$ & \\
\hline Total & 5.2 & & & 5.0 & & & 5.2 & & & 5.4 & & & \\
\hline RII & & & & $p^{*}$ & & & $p^{*}$ & & & $p^{*}$ & & & $\mathrm{p}^{*}$ \\
\hline Overall & & 2.45 & $(2.31,2.59)$ & & 1.60 & $(1.51,1.70)$ & & 1.52 & $(1.44,1.61)$ & & 1.75 & $(1.65,1.86)$ & \\
\hline Marital status & & & & $<0.001$ & & & 0.001 & & & 0.004 & & & 0.18 \\
\hline Married & & 2.31 & $(2.16,2.46)$ & & 1.48 & $(1.38,1.59)$ & & 1.43 & $(1.32,1.54)$ & & 1.65 & $(1.51,1.79)$ & \\
\hline Single & & 1.76 & $(1.51,2.06)$ & & 1.14 & $(1.00,1.29)$ & & 1.11 & $(0.99,1.26)$ & & 1.45 & $(1.30,1.62)$ & \\
\hline Other & & 1.45 & $(1.12,1.88)$ & & 1.20 & $(0.97,1.49)$ & & 1.27 & $(1.05,1.53)$ & & 1.50 & $(1.30,1.73)$ & \\
\hline Maternal age & & & & $<0.001$ & & & 0.002 & & & 0.001 & & & 0.005 \\
\hline$<20$ & & 1.48 & $(1.26,1.74)$ & & 1.12 & $(0.95,1.33)$ & & 1.03 & $(0.84,1.25)$ & & 1.39 & $(1.12,1.73)$ & \\
\hline $20-34$ & & 2.35 & $(2.20,2.52)$ & & 1.55 & $(1.45,1.66)$ & & 1.50 & $(1.41,1.61)$ & & 1.66 & $(1.55,1.78)$ & \\
\hline$\geqslant 35$ & & 3.08 & $(2.50,3.80)$ & & 1.69 & $(1.37,2.08)$ & & 1.69 & $(1.40,2.03)$ & & 2.12 & $(1.81,2.48)$ & \\
\hline Maternal height & & & & 0.54 & & & 0.39 & & & 0.27 & & & $<0.001$ \\
\hline$<155 \mathrm{~cm}$ & & 2.15 & $(1.89,2.44)$ & & 1.38 & $(1.20,1.58)$ & & 1.32 & $(1.13,1.53)$ & & 1.54 & $(1.31,1.80)$ & \\
\hline $155 \mathrm{~cm}-164 \mathrm{~cm}$ & & 2.36 & $(2.19,2.56)$ & & 1.55 & $(1.43,1.68)$ & & 1.43 & $(1.32,1.55)$ & & 1.69 & $(1.56,1.84)$ & \\
\hline$>164 \mathrm{~cm}$ & & 2.33 & $(2.07,2.62)$ & & 1.51 & $(1.35,1.69)$ & & 1.55 & $(1.40,1.72)$ & & 1.71 & $(1.55,1.87)$ & \\
\hline Parity & & & & 0.01 & & & $<0.001$ & & & $<0.001$ & & & $<0.001$ \\
\hline 0 & & 2.07 & $(1.91,2.25)$ & & 1.24 & $(1.14,1.35)$ & & 1.25 & $(1.15,1.36)$ & & 1.31 & $(1.20,1.42)$ & \\
\hline $1-2$ & & 2.48 & $(2.27,2.72)$ & & 1.81 & $(1.65,1.99)$ & & 1.69 & $(1.54,1.85)$ & & 2.04 & $(1.86,2.23)$ & \\
\hline $3+$ & & 2.44 & $(2.00,2.98)$ & & 1.63 & $(1.32,2.00)$ & & 1.38 & $(1.12,1.70)$ & & 2.17 & $(1.77,2.66)$ & \\
\hline
\end{tabular}

It would also have been of interest to look at trends in stillbirths and perinatal deaths. In this study the social class information was obtained from birth registrations but stillbirths are not registered this way so social class information was not available for stillbirths in Scotland over the entire study period. The General Register Office for Scotland (GROS) reports stillbirths by social class between 1946 and $1997 .{ }^{17}$ There are differences in stillbirth rates by social class in Scotland. However, previous research found that the influence of social class on perinatal mortality (stillbirths and neonatal deaths) remained unchanged between 1960 and $1982 .{ }^{18}$

The social class measure used was derived from the occupation of the father, or the mother if the father was not present. Although parental social class is associated with adverse pregnancy outcomes ${ }^{4}$ there are problems with

Table 5 Small for gestational age prevalence, odds ratios $(95 \% \mathrm{Cl})$ by social class, and RIl by maternal factors and time, Scotland 1980-2000

\begin{tabular}{|c|c|c|c|c|c|c|c|c|c|c|c|c|c|}
\hline \multirow[b]{2}{*}{ Social class } & \multicolumn{3}{|c|}{ 1980-1984 } & \multicolumn{3}{|c|}{ 1985-1989 } & \multicolumn{3}{|c|}{ 1990-1994 } & \multicolumn{3}{|c|}{ 1995-2000 } & \\
\hline & $\%$ & OR & $95 \% \mathrm{Cl}$ & $\%$ & OR & $95 \% \mathrm{Cl}$ & $\%$ & OR & $95 \% \mathrm{Cl}$ & $\%$ & OR & $95 \% \mathrm{Cl}$ & \\
\hline 1 & 3.5 & 1 & & 3.2 & 1 & & 2.4 & 1 & & 2.3 & 1 & & \\
\hline II & 4.1 & 1.16 & $(1.07,1.27)$ & 3.7 & 1.17 & $(1.07,1.28)$ & 3.4 & 1.41 & $(1.27,1.56)$ & 3.1 & 1.35 & $(1.21,1.50)$ & \\
\hline IIInm & 6.1 & 1.80 & $(1.66,1.96)$ & 5.1 & 1.63 & $(1.49,1.78)$ & 4.8 & 2.03 & $(1.83,2.25)$ & 4.3 & 1.94 & $(1.74,2.15)$ & \\
\hline IIIm & 6.1 & 1.79 & $(1.66,1.94)$ & 5.1 & 1.64 & $(1.51,1.79)$ & 4.6 & 1.95 & $(1.76,2.15)$ & 4.3 & 1.93 & $(1.75,2.14)$ & \\
\hline IV & 6.9 & 2.06 & $(1.90,2.23)$ & 6.2 & 2.00 & $(1.83,2.18)$ & 5.5 & 2.34 & $(2.11,2.58)$ & 5.3 & 2.42 & $(2.18,2.68)$ & \\
\hline V & 7.9 & 2.35 & $(2.16,2.56)$ & 6.6 & 2.14 & $(1.94,2.35)$ & 6.0 & 2.53 & $(2.28,2.82)$ & 5.1 & 2.28 & $(2.03,2.57)$ & \\
\hline Undetermined & 10.4 & 3.21 & $(2.92,3.53)$ & 7.5 & 2.46 & $(2.24,2.71)$ & 6.3 & 2.69 & $(2.43,2.99)$ & 5.9 & 2.71 & $(2.44,3.00)$ & \\
\hline Total & 6.0 & & & 5.2 & & & 4.7 & & & 4.3 & & & \\
\hline RII & & & & $p^{*}$ & & & $p^{*}$ & & & $\mathrm{p}^{*}$ & & & $p^{*}$ \\
\hline Overall & & 2.41 & $(2.29,2.55)$ & & 2.21 & $(2.08,2.34)$ & & 2.28 & $(2.14,2.42)$ & & 2.49 & $(2.34,2.66)$ & \\
\hline Marital status & & & & $<0.001$ & & & $<0.001$ & & & $<0.001$ & & & $<0.001$ \\
\hline Married & & 2.14 & $(1.99,2.30)$ & & 2.08 & $(1.94,2.23)$ & & 2.17 & $(2.00,2.36)$ & & 2.24 & $(2.03,2.48)$ & \\
\hline Single & & 1.36 & $(1.21,1.54)$ & & 1.33 & $(1.17,1.50)$ & & 1.39 & $(1.24,1.57)$ & & 1.57 & $(1.40,1.76)$ & \\
\hline Other & & 1.47 & $(1.19,1.80)$ & & 1.46 & $(1.19,1.80)$ & & 1.43 & $(1.18,1.72)$ & & 2.19 & $(1.87,2.56)$ & \\
\hline Maternal age & & & & $<0.001$ & & & $<0.001$ & & & $<0.001$ & & & $<0.001$ \\
\hline$<20$ & & 1.39 & $(1.18,1.63)$ & & 1.27 & $(1.07,1.52)$ & & 0.97 & $(0.79,1.19)$ & & 0.98 & $(0.77,1.23)$ & \\
\hline $20-34$ & & 2.47 & $(2.33,2.63)$ & & 2.18 & $(2.04,2.33)$ & & 2.31 & $(2.15,2.48)$ & & 2.46 & $(2.28,2.65)$ & \\
\hline$\geqslant 35$ & & 3.39 & $(2.73,4.21)$ & & 3.83 & $(3.04,4.83)$ & & 3.15 & $(2.56,3.88)$ & & 4.01 & $(3.54,4.79)$ & \\
\hline Maternal height & & & & 0.03 & & & $<0.001$ & & & 0.56 & & & $<0.001$ \\
\hline$<155 \mathrm{~cm}$ & & 1.81 & $(1.63,2.00)$ & & 1.54 & $(1.37,1.73)$ & & 1.95 & $(1.70,2.22)$ & & 1.78 & $(1.54,2.07)$ & \\
\hline $155 \mathrm{~cm}-164 \mathrm{~cm}$ & & 2.10 & $(1.95,2.25)$ & & 1.89 & $(1.75,2.05)$ & & 1.96 & $(1.80,2.13)$ & & 2.16 & $(1.97,2.36)$ & \\
\hline$>164 \mathrm{~cm}$ & & 2.37 & $(2.08,2.71)$ & & 2.48 & $(2.17,2.82)$ & & 2.19 & $(1.93,2.49)$ & & 2.72 & $(2.41,3.08)$ & \\
\hline Parity & & & & $<0.001$ & & & $<0.001$ & & & $<0.001$ & & & $<0.001$ \\
\hline 0 & & 1.79 & $(1.67,1.93)$ & & 1.54 & $(1.43,1.67)$ & & 1.73 & $(1.60,1.88)$ & & 1.74 & $(1.59,1.90)$ & \\
\hline $1-2$ & & 2.33 & $(2.14,2.53)$ & & 2.36 & $(2.14,2.60)$ & & 2.40 & $(2.17,2.66)$ & & 3.03 & $(2.72,3.36)$ & \\
\hline $3+$ & & 2.14 & $(1.74,2.63)$ & & 2.53 & $(2.00,3.20)$ & & 2.40 & $(1.86,3.09)$ & & 3.08 & $(2.37,4.00)$ & \\
\hline
\end{tabular}




\section{Key points}

- Inequalities in adverse perinatal outcomes in Scotland increased during the 1990s in all strata defined by maternal characteristics

- Inequalities in LBW, preterm births, and SGA were greatest in married, older, taller, and high parity mothers

- For women with parity one or more, and for mothers who were not married, inequalities in LBW and SGA births were greater by the end of the 1990s than at the start of the 1980s

assigning occupational social class to mothers. ${ }^{19}$ The registrar general's occupational social class is based on occupation and women are more likely to be looking after the home and family or never to have worked, and therefore cannot be assigned their own social class. We saw a large rise in the mothers with undetermined social class to $15 \%$ of the study population in the late 1990s. The rise in the proportion of mothers with undetermined social class partly reflects changes in the marital status distribution over time. Within the undetermined group $43 \%$ of mothers were married in the early 1980s compared with $18 \%$ in the late 1990s while $43 \%$ were single in the early 1980s rising to $64 \%$ in the late 1990 s and the "other" marital status group accounted for 13\% of the undetermined group in 1980-84 and 18\% in 1995-2000. No information was available to show how the different components of this undetermined group changed over time. The undetermined social class contains a heterogeneous mix of people, but it was evident that they experienced the worst perinatal outcomes so this group was placed at the bottom of the social class hierarchy when creating the RII. This measure controlled for the changing social class distribution over time.

Lone mothers are at greater socioeconomic disadvantage than both married and cohabiting mothers, and also suffer greater ill health. ${ }^{70}$ Despite this, inequalities in adverse perinatal events were lower in single than married and cohabiting mothers. For married mothers and cohabiting mothers social class is likely to be derived from the husband or partner but for the single mother this is likely to be their own social class. In the 1990s the changes to the distribution of social class were similar across all marital status groups, with the exception of the undetermined social class, which increased in the single and other marital status mothers but remained constant in the married mothers. Among those with undetermined social class married mothers may be at a greater socioeconomic disadvantage than single mothers, as for married mothers neither the mother nor the father can be assigned a social class. This could explain why inequalities among married mothers are greater than for single mothers. The recent increases in inequalities were most pronounced among single mothers and those of other marital status; both groups had higher inequalities by the end of the 1990s than at the beginning of the 1980s.

Inequalities by maternal age were lowest in mothers aged less than 20. During the early 1990s there was no significant difference between the top and bottom of the social class hierarchy in this age group. So although young maternal age is a risk factor for adverse perinatal outcomes, ${ }^{4}$ we found that the relation between social class and adverse perinatal outcomes in younger mothers is not that strong. However, there are problems with assigning social class to teenage mothers as many of them will be in the undetermined group. ${ }^{19}$
The proportion of births to older mothers increased throughout the 1980s and $1990 \mathrm{~s}^{11}$ and this group is also at higher risk for adverse perinatal outcomes. ${ }^{4}$ In this study we saw that this age group experienced the greatest inequalities. The detrimental effect of smoking increases with the age of the mother, ${ }^{21}$ so some of the inequality may have been explained by smoking during pregnancy as this is also related to social class (smoking rates being higher in the lower social classes)..$^{82}$ Elsewhere half the excess risk of adverse perinatal outcomes in the lowest socioeconomic group was explained by maternal smoking. ${ }^{9}$

Smoking status during pregnancy has only been collected routinely in Scotland from 1992 and there are concerns about the quality of these data, and care should be taken in interpreting the result using this information. ${ }^{23}$ However, inequalities in smoking during pregnancy, measured by area deprivation, reduced in Scotland during the 1990s. ${ }^{24}$

Crude analysis of the data (not shown) looking at the interactions between smoking status and RII showed that when smoking was coded as smokers, non-smokers, and not known smoking status, inequalities in perinatal outcomes were significantly higher for mothers with not known smoking status than both the smokers and non-smokers. For non-smokers and smokers the RII for LBW and preterm births increased throughout the 1990s; however for SGA they decreased slightly. For the mothers whose smoking status was not known the RII for LBW was similar in 1992-94 and 1995-2000, it decreased slightly for preterm births and increased over time for SGA.

Socioeconomic inequalities in height are well reported ${ }^{25}$ and maternal height is also associated with LBW. ${ }^{26}$ We found the greatest inequalities among the tallest mothers. The mean height of mothers in this study increased steadily over time. There is evidence to show that differences in height by social class are decreasing over time ${ }^{25}$; however, inequalities in adverse perinatal events persist and have been increasing throughout the 1990s for women of all heights.

The Scottish Morbidity Record collects information on clinical and demographic characteristics and outcomes for all patients discharged from Scottish maternity hospitals. The register is subjected to regular quality assurance checks and has been greater than $99 \%$ complete since the late 1970s. ${ }^{27} 28$ Maternal height is a mandatory but not high priority data item collected on SMR2 forms. ${ }^{29}$ The proportion of mothers whose height was missing on the hospital discharge form was rather high in the late 1990s (40\% of all missing height records) and the amount of missing height information varied by health board. Mothers with missing height had a higher prevalence of both LBW and preterm births. However, the proportion of mothers with missing height was constant across social class. Analysis looking at the interactions between the other maternal factors and RII including mothers with missing height in the late 1990s showed similar trends and estimates of inequality estimates as that excluding mothers with missing height (results not shown).

Inequalities in adverse perinatal outcomes in women of parity one or more were significantly greater than for primiparous women. Increases in inequalities in the 1990s were also more pronounced among women of parity $1-2$ or $3+$. Both high parity and low social status are independent risk factors for a short interpregnancy interval, ${ }^{30}$ which can lead to ill health for both the mother and the child. ${ }^{31}$ Inequalities in the high parity group and among women of parity 1-2 were the same or greater in the late 1990s than they were in the early 1980s.

Over the past two decades in Scotland there have been changes in modes of delivery, in particular a large rise in the caesarean section rate that is associated with both birth weight and gestation. ${ }^{32}$ There are variations between health 
board areas in the rates of different modes of delivery and pregnancy outcomes. ${ }^{33}$ Some of these differences may be because of changes social circumstances of mothers over time. Further work investigating inequalities in caesarean section rates is ongoing.

By looking at the interactions with other maternal factors we were able to identify in which groups the inequalities were greatest and how they had changed over time. We showed that it is not just the most vulnerable groups of women where inequalities are widening. Inequalities in perinatal outcomes have health service resource implications, as poorer outcomes are more likely to lead to intensive neonatal care. Further research into the provision of prenatal and delivery services by social groups is needed. To reduce inequalities later in life it is important to reduce inequalities at birth, ${ }^{16}$ and therefore it is important to continue to monitor and understand trends and inequalities in perinatal health.

\section{CONCLUSIONS}

Despite decreasing during the 1980s, inequalities in LBW, preterm, and SGA births increased during the 1990s in all strata defined by maternal characteristics. For women of parity one or more and for mothers who were not married, inequalities were greater by the end of the 1990s than at the start of the 1980s.

\section{ACKNOWLEDGEMENTS}

We thank the Information and Statistics Division of the NHS in Scotland for providing the data.

\section{Authors' affiliations \\ L Fairley, A H Leyland, MRC Social and Public Health Sciences Unit, University of Glasgow, Glasgow, UK}

Funding: the Social and Public Health Sciences Unit is jointly funded by the Medical Research Council and the Chief Scientist Office of the Scottish Executive.

Competing interests: none declared.

Ethics approval: ethical approval was not required because the data requested were historic and anonymised, but an application to use the data was approved by the Privacy Advisory Committee of ISD Scotland.

\section{REFERENCES}

1 Macfarlane A, Mugford M. Birth counts: statistics of pregnancy and childbirth. London: HMSO, 1984

2 ISD Scotland. Scottish perinatal and infant mortality and morbidity report. Edinburgh: ISD Scotland, 2003.

3 Barker DJP. Fetal and infant origins of adult disease BMJ Books, 1992.

4 de Sanjose S, Roman E. Low birth weight, preterm, and small for gestational age babies in Scotland, 1981-1984. J Epidemiol Community Health 1991:45:207-10.

5 Maher J, Macfarlane A. Trends in live births and birthweight by social class, marital status and mother's age, 1976-2000. Health Statistics Quarterly 2004:34-43
6 Macfarlane A, Moser K. Social inequalities. In: The health of children and young people. London: Office for National Statistics, 2004.

7 Shouls S, Whitehead M, Burstrom B, et al. The health and socio-economic circumstances of British lone mothers over the last two decades. Popul Trends 1999:95:41-6.

8 Kramer MS, Seguin L, Lydon J, et al. Socio-economic disparities in pregnancy outcome: why do the poor fare so poorly? Paediatr Perinat Epidemiol 2000; 14:194-210.

9 Gissler M, Merilainen J, Vuori E, et al. Register based monitoring shows decreasing socioeconomic differences in Finnish perinatal health. J Epidemiol Community Health 2003;57:433-9.

10 Bai J, Wong FWS, Bauman A, et al. Parity and pregnancy outcomes. Am J Obstet Gynecol 2002;186:274-8.

11 Fairley L. Changing patterns of inequality in birthweight and its determinants: a population based study Scotland 1980-2000. Paediatr Perinat Epidemiol 2005; 19:342-51.

12 Moser K, Li L, Power C. Social inequalities in low birth weight in England and Wales: trends and implications for future population health. J Epidemiol Community Health 2003;57:687-91.

13 Claussen B, Davey Smith G, Thelle D. Impact of childhood and adulthood socioeconomic position on cause specific mortality: the Oslo mortality study. $J$ Epidemiol Community Health 2003;57:40-5.

14 Regidor E. Measures of health inequalities: part 2. J Epidemiol Community Health 2004:58:900-3.

15 Davey Smith G, Hart C, Hole D, et al. Education and occupational social class: which is the more important indicator of mortality risk? J Epidemiol Community Health 1998;52:153-60.

16 Spencer N, Logan S. Social influences on birth weight. Arch Dis Child 2002;86:F6-7.

17 General Register Office for Scotland. Annual report of the registrar general for Scotland. Edinburgh: General Register Office for Scotland, 1997.

18 Forbes JF, Pickering R. Influence of maternal age, parity and social class on perinatal mortality in Scotland: 1960-82. J Biosoc Sci 1985;17:339-49.

19 Cooper J, Botting B. Analysing fertility and infant mortality by mother's social class as defined by occupation. Popul Trends 1992;70:15-21.

20 Kiernan K, Smith K. Unmarried parenthood: new insights from the millennium cohort study. Popul Trends 2003;114:26-33.

21 Bonellie SR. Effect of maternal age, smoking and deprivation on birthweight. Paediatr Perinat Epidemiol 2001;15:19-26.

22 Rush D, Cassano P. Relationship of cigarette smoking and social class to birth weight and perinatal mortality among all births in Britain, 5-11 April 1970 $J$ Epidemiol Community Health 1983:37:249-55

23 ISD Scotland. Accuracy of smoking data. http://www.isdscotland.org/isd/ info3.jsp?pContentID = 2122\&p_applic = CCC\&p_service $=$ Content. show \& (accessed 27 Jul 2005).

24 Report of the Measuring Inequalities in Health Working Group. Inequalities in health. Edinburgh: Measuring Inequalities in Health Working Group, 2003.

25 Power C, Manor O, Li L. Are inequalities in height underestimated by adult social position? Effects of changing social structure and height selection in a cohort study. BMJ 2002;325:131-4.

26 Meis PJ, Michielutte R, Peters TJ, et al. Factors associated with term low birthweight in Cardiff, Wales. Paediatr Perinat Epidemiol 1997;11:287-97.

27 Smith GCS, Pell JP, Dobbie R. Interpregnancy interval and risk of preterm birth and neonatal death: retrospective cohort study. BMJ 2003;327:313-20.

28 Cole SK. Scottish maternity and neonatal records. In: Chalmers I, Mcllwaine GM, eds. Perinatal audit and surveillance. London: Royal College of Obstetricians and Gynaecologists, 1980:39-51.

29 Quality Assessment and Accreditation Team and Scottish Clinical Coding Team. Summary of Preliminary Findings of SMRO2(COPPISH) Project, 1997

30 Kaharuza FM, Sabroe S, Basso O. Choice and chance: Determinants of short interpregnancy intervals in Denmark. Acta Obstet Gynecol Scand 2001;80:532-8.

31 Rousso D, Panidis D, Gkoutzioulis F, et al. Effect of the interval between pregnancies on the health of mother and child. Eur J Obstet Gynecol Reprod Biol 2002; 105:4-6.

32 ISD Scotland. Operative vaginal delivery in Scotland. A 20 year overview: births in Scotland publication series. Vol 4. Edinburgh: ISD Scotland, 2003.

33 ISD Scotland. NHS board variations in maternity care and outcomes: births in Scotland publication series. Vol 5. Edinburgh: ISD Scotland, 2005. 